\title{
Loading bay booking and control for urban freight
}

\author{
Fraser McLeod ${ }^{1}$ and Tom Cherrett ${ }^{2}$ \\ Transportation Research Group, School of Civil Engineering and the Environment, \\ University of Southampton, United Kingdom.
}

E-Mail: F.N.McLeod@soton.ac.uk and T.J.Cherrett@soton.ac.uk

\begin{abstract}
This paper investigates the concept of a loading bay advance booking and control system for delivery and service vehicle drivers. A case study of Winchester High Street is presented to illustrate the potential impact of such a system. A number of operating scenarios were considered based on the punctuality of deliveries and service visits using a comprehensive database of vehicle arrival patterns. The main performance measures used were adherence to schedule, delivery time and the use of unloading points, with reference to their desirability, both from the freight vehicle drivers' and other road users' viewpoints. The research has highlighted the different factors that would need to be taken into account when evaluating a managed loading bay system, from the standpoints of the various actors involved, including the traffic authority, freight operator, driver, retailer and other road users.
\end{abstract}

Keywords: freight, delivery, loading bay, service vehicles, urban

\section{Introduction}

Drivers of delivery/collection and service vehicles operating in urban centres often encounter difficulties finding suitable, convenient places to stop their vehicles in order to load/unload goods, or carry tools/maintenance equipment to the businesses being visited. This paper investigates the idea of a managed, bookable loading bay system, whereby advance bookings can be made by users and enforcement and control measures are used to ensure effective operation. The aims of such a system are to offer guaranteed loading and unloading places, and to discourage undesirable driver behaviour associated with unloading such as double parking, parking on the pavement and causing obstructions to pedestrians and other road users. Such a system could be facilitated through the use of wireless communications between freight vehicles, freight distribution centres and traffic control centres, a concept that has been proposed and investigated by the EU-funded projects SmartFreight (www.smartfreight.info) and CVIS (www.cvisproject.org). Although most cities do not currently take an active role in managing individual freight delivery movements, it is conceivable that this may happen in the future, particularly where traffic problems are exacerbated by freight deliveries, and we may see a move to an 'air traffic control' type, last-mile managed approach.

\section{Literature review}

Many different types of booking system applications can be found in the literature but few, if any, can be readily applied to the problem addressed here. The concept of 
over-booking, with the expectation of some bookings being subsequently cancelled or the customer not showing up, is seen in the airline industry, among other application areas. This requires a trade-off between the costs associated with not providing the service promised to some customers, if over-booked, and the costs associated with having unsold seats, where cancelled bookings are eligible for refunds (Feng and Xiao, 2006). In principle, this concept could be applied to the loading bay booking system here, if the number of users of the system was high and cancellations a common feature, however it was not considered to be appropriate for this study involving the relatively small city of Winchester, UK.

Some authors have considered the idea of reserving time slots to use a particular road, typically a motorway, with the objectives of providing reliable journey times and more efficient use of the road space (Wong, 1997; de Feijter et al, 2004; Edara and Teodorovic, 2008). The concept of highway reservation is similar, in some respects, to the concept investigated here, in that (i) reservations are made in advance (whether days, hours or minutes in advance); and (ii) some control procedures are specified to cater for vehicles not arriving at their booked times. However, the highway reservation problem is somewhat different from the one under investigation here as the highway has significantly more users and vehicles can enter and exit the highway from different points (motorway junctions). Consequently, the algorithms that have been developed to solve the highway reservation problem cannot be readily applied to the loading bay reservations.

Advance freight vehicle booking systems are in use at some port authorities, including Southampton and Felixstowe. By introducing a mandatory booking system for all trucks visiting Southampton container terminal, the Port of Southampton has reduced levels of queuing and improved reliability of deliveries (McCrindle, 2008). An observed effect at the Port of Southampton is a spread in the delivery peak, achieved by limiting the number of slots available at a particular time and by charging users more to use the port during the busiest time periods. The booking system is also perceived to improve port security.

A city centre loading bay booking system would likely have to include several different loading bay locations to meet the needs of the users. For a large city, the number of bays needed may be considerable: for example the Mayor of Paris stated that 10,000 loading bays were needed (Browne et al, 2007). However, for a small city, such as the case study site of Winchester, the number could be small, or bookings could be applied to only a small subset of available bays and/or could be restricted to certain categories of user, for example, according to vehicle size, weight or engine emissions standard.

A survey of loading bays in Paris indicated that they were only used legitimately for $6 \%$ of the time, being unused for $47 \%$ of the time and occupied illegally by cars for the remaining $47 \%$ of the time (Browne et al, 2007). These statistics indicate the need for enforcement of loading bay access, if a bookable system is to be successful. Also important is that the bays achieve a high rate of legitimate utilisation in order to be seen as credible and be respected by the majority of other road users. Tight enforcement of general parking and unloading regulations 
would also be needed, since delivery drivers, given the option of unloading directly outside the store would naturally attempt to do so, even if it contravened loading restrictions. The Paris survey suggested that $75 \%$ of all deliveries were made illegally but few fines had been issued. Similar leniency has been adopted in some London boroughs, where, perhaps due to lack of suitable loading bays, parking attendants have been instructed not to issue fines to drivers of goods vehicles loading or unloading between 08.30 and 11.00 (Browne et al, 2007).

A 3-month trial of a bookable loading bay system was undertaken by the CVIS (Cooperative Vehicle-Infrastructure Systems) (CVIS, 2010) project. This trial took place in Earl's Court, London and comprised one bookable loading bay, eight freight operating companies, and ten vehicles, although only seven of these were reported as being active. The trial demonstrated the technical feasibility of the communications between vehicles and roadside infrastructure to enable the management of loading bay bookings and control. The prototype system permitted users to amend their reservations, if arriving early or late, although it was observed that there were 7 occasions where a user entered the bay before the booked time and 10 occasions where a user departed after the booked time. A strict enforcement regime was used for the trial, with enforcement officers moving on 80 vehicles and issuing 15 penalty charge notices to illegal users of the bay. If the system was to be implemented on a wide scale it was considered that number plate recognition technology would be needed for enforcement.

\section{Description of the problem}

The objectives of this research were to evaluate what benefits might accrue from using bookable loading bays in urban areas for use by delivery and service vehicles, where the benefits may be due to:

(1) Freight drivers being provided with pre-booked unloading places.

(2) The bookable loading bays being located advantageously, in terms of time needed to reach them and then time needed to move the goods (or servicing equipment) from the unloading point to the store.

(3) A reduction in lorries causing obstructions to other roads users.

In practice, these 'bays' could correspond to either on-street (Figure 1) or offstreet (Figure 2) unloading areas. Bookings were assumed to be mandatory for all users of the loading bays, however, it was assumed that some vehicles would be early for their booking while others would be late, as would be likely in practice, due to difficulties associated with maintaining schedules (Fowkes et al, 2004). For this reason, the loading bay system requires not only advance bookings but also control procedures for dealing with such eventualities. 


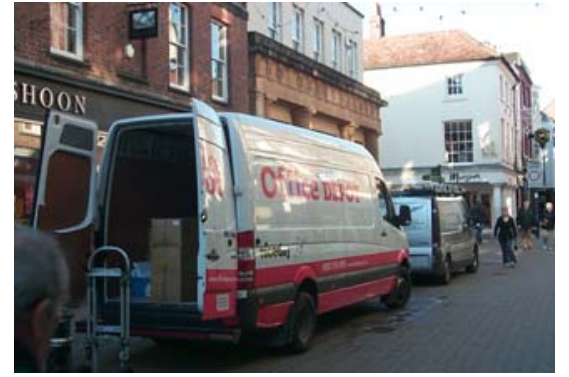

Figure 1 - On street unloading area

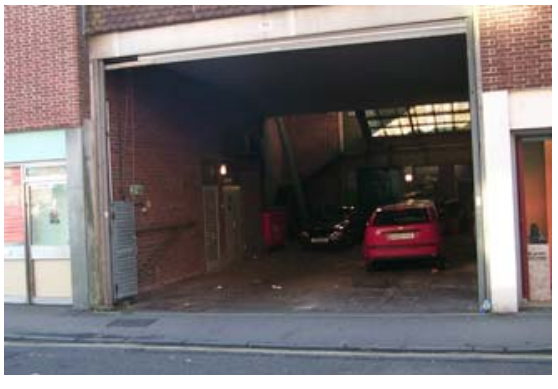

Figure 2 - Off-street loading bay

\section{The case study area}

The modelled loading bays were based on the existing freight unloading points in and around Winchester High Street (Figure 3). These unloading points were determined from a number of on-street observations that were made of freight unloading behaviour in Winchester as part of a wider project called Green Logistics (www.greenlogistics.org.uk). A section of Winchester High Street, about 180m long, is fully pedestrianised (the hatched area of Figure 3 between points 1 and 2) and there is also a vehicle ban (buses excepted) between 10:00 and 16:00 hours on sections (45m long at the 'top' end (left hand side of map) and 270m long at the 'bottom' end (right hand side of map)) either side of the pedestrianised area.

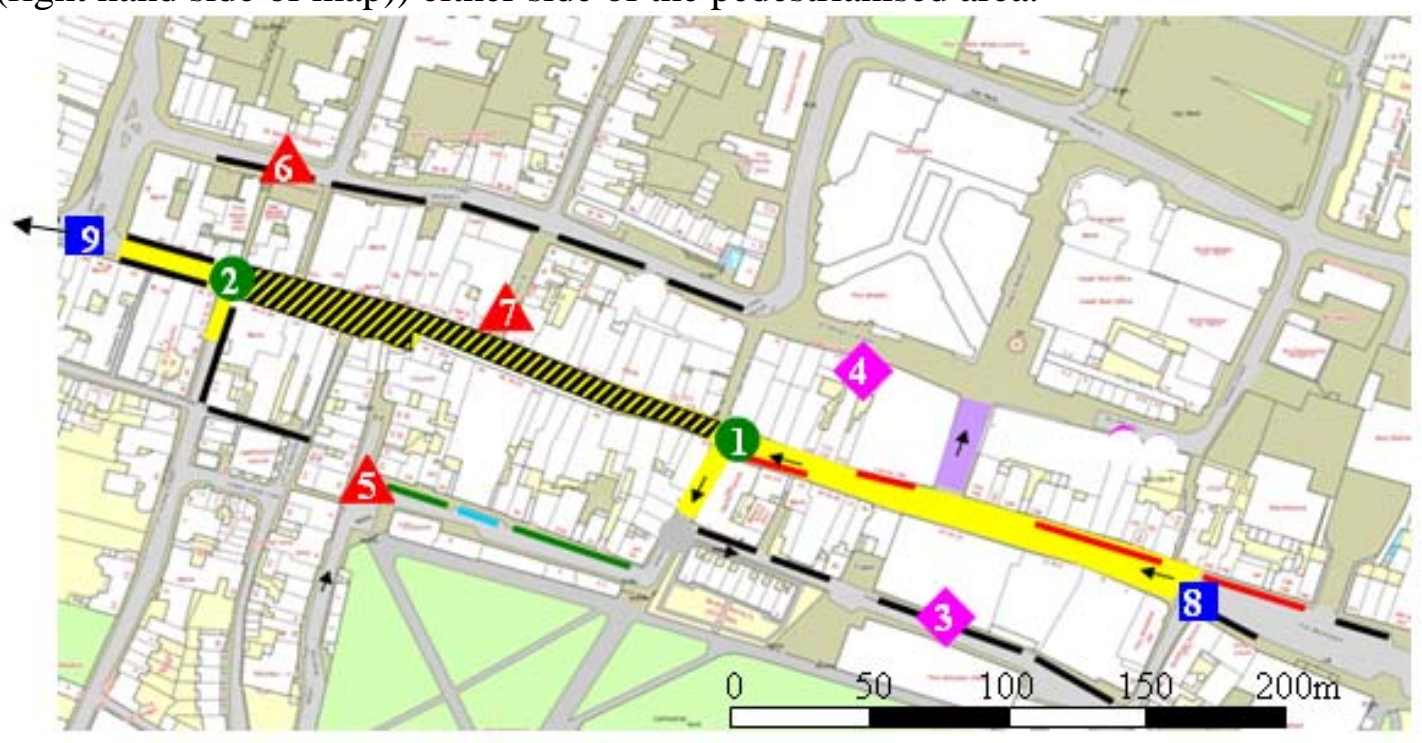

Key

Bookable loading bays at "bottom end” (1) and "top end” (2) of the High Street.

Private loading bays used before and after; not bookable.

Freight unloading points used in the before case but banned from use in the after case, as they were considered to be undesirable from the viewpoint of pedestrians and traffic. 
Other freight unloading points that may be used in the before and after cases, particularly during the restricted time period (1000-1600). Note: point no. 9 is some $75 \mathrm{~m}$ or so off the map.

Figure 3. Freight unloading points on or near Winchester High Street

From a survey of $69 \%(n=83)$ of the 120 business managers on Winchester High Street, approximately 618 core goods delivery visits may be made each week to businesses on the High Street ('core goods' being defined as those which were of fundamental importance to the business activity), (Cherrett et al, 2010; Cherrett et al, 2009). The total unloading time across the whole High Street, excluding banks and building societies (107 businesses), was estimated to be around 173 hours per week with $73 \%$ of respondents stated that unloading was undertaken on-street, with the majority being done on public roads. This equates to approximately 126 hours of stationary delivery vehicle activity per week serving the High Street businesses (21 hours per day assuming a 6 day delivery week). In terms of service vehicle impacts, the whole High Street, excluding banks and building societies was estimated to receive 814 service visits per week, comprising 496 postal deliveries and 318 other types of service visit. The average duration of a service visit was estimated to be 30 minutes (including postal deliveries) or 37 minutes (excluding postal deliveries) with approximately $70 \%$ being made by motorised transport.

Two bookable loading bays were modelled, located at either end of the pedestrianised area (numbered 1 and 2 in Figure 1), but within the currently restricted area, giving users improved access to the High Street. These bays were assumed to operate from 06:00 to 16:00 hours, accommodating either one or two vehicles at a time, depending on the scenario being considered. While both locations may have the physical space available to allow more than two lorries at a time these scenarios were chosen to represent examples of restricted access. In reality, Winchester City Council would have to decide whether allowing any such access would be acceptable.

The bookable loading bay system modelled here comprised two parts:

(1) An advance booking system, which permitted users to book loading bay time slots ahead of their arrival in the city (e.g. some days or hours ahead; last minute bookings were not considered here).

(2) A control system, which dealt with the day-to-day operational issues (e.g. vehicles arriving early or late).

\section{Methodology}

The advance booking and control system models were programmed in Fortran, based on the rules and assumptions described below:

\subsection{Advance booking system} involved:

The advance booking system method used was relatively straightforward and

(1) Bookable time slots of 15 minutes duration (e.g. 09:00-09:15). 
(2) An input list of vehicles, in booking order, with each vehicle requesting their preferred entry time to the loading bay and the number of time slots required.

(3) Allocation of time slots to each vehicle in turn. If the requested slots were not available then the nearest ones available, if any, would be allocated instead.

It should be noted that, with these rules, vehicles higher up the list would tend to receive their desired bookings whereas vehicles lower down the list would not necessarily be able to do so due to bookings made earlier. In practice, the order in which vehicles book slots could be left entirely open, that is, a first-come, first-served system, or some form of priority booking could be used, with certain groups of vehicle, or operator, being given the opportunity to book slots ahead of others. For example, in the results presented here rigid-bodied heavy goods vehicles undertaking deliveries (and/or collections), subsequently referred to in this paper as 'rigids', were allowed to book before vans undertaking deliveries (and/or collections) (e.g. couriers) who, in turn, were allowed to book before service vehicles. Whether priority booking would be desirable or not would depend on the individual city/scheme and its objectives.

For simplicity, it was assumed here that all allocated bookings would be accepted for use. In practice, though, some time slots offered by the allocation system would likely be rejected as being too early or too late and the driver (or freight distribution manager) would decide to make alternative arrangements, such as unloading elsewhere. The likely effect would be a slight reduction in the use of the bookable loading bays with corresponding increased use of other freight unloading points. It was also assumed that, for users of the bookable loading bays, an advance booking was mandatory, that is, it was not possible to book at the last minute.

\subsection{Control system}

The control system method involved a set of rules for dealing with the day-today situations that would likely occur in practice. These rules are summarised here, including some discussion of their implications:

- Users of the system were detected on the outskirts of the city centre (in practice this would need communications infrastructure on all of the main approach roads in two-way communication with freight vehicles (Natvig, 2010).

- The vehicle bookings were checked to determine whether the vehicle was on time, early or late for its booking. This required estimates of the times needed to travel from the detection points to the loading bays.

- Vehicles arriving early for their booking could proceed immediately to the bay if it was expected to be available or they were instructed to wait in a designated holding area until the bay was expected to be available. In practice, holding areas could be located at park-and-ride sites, lay-bys, or other parking areas. The phrase 'expected to be available' is used rather than 'available' as there is a time difference between the time of detection and the time of arrival at the loading bay. If this time difference is significant (more than 5 minutes, say) then the prediction of the loading bay availability is needed to avoid the delays that would occur if vehicles had to wait at the holding area until the bay was actually free. The loading bay availability was not assumed to be determined by the vehicle bookings, but by the actual usage of the bays and an expected dwell time parameter value which was specified for each vehicle. In 
practice, this would require communications infrastructure at the loading bays to monitor entry and exit times. In addition, the system could require the users to provide expected dwell time data or such data could be recorded by the system over time. Naturally, any prediction is subject to error. The implications of errors in predicting the availability of the bay are that either:

(i) A vehicle could arrive at the bay before it is available, which may cause congestion problems near the bay.

(ii) A vehicle may be delayed for longer than necessary in gaining access to the bay, in the case that the previous vehicle departed sooner than expected.

- Vehicles arriving late for their booking were allowed to use any remaining time left on the booking subject to a minimum use requirement which was specified as the larger of $25 \%$ of the expected dwell time or five minutes. Otherwise, an alternative freight unloading point had to be used. Late vehicles also had the opportunity to extend the booking if succeeding time slots were available. If the booking could not be extended but there was some time remaining on the booking then it was assumed that the vehicle partly unloaded from the booked bay but then had to move to an alternative freight unloading point to complete the delivery and a 5-minute 'moving delay' was assumed.

- A 'strict enforcement' policy was assumed whereby the bay would not be used by non-users of the system (e.g. private cars) and users of the bays were not allowed to overrun their original or extended booking.

- Once a vehicle exited the loading bay, its booking was cancelled to allow following vehicles, particularly early vehicles, to gain access to the bay early. Another situation where such a system might consider cancelling a booking is when it recognises that a vehicle is too late to use its booking. This would provide some additional loading bay availability in the case of a "no show". This option was not modelled here however.

\subsection{Input data}

Three types of input data were required by the control system model: road network data, vehicle data and booking data.

\subsubsection{Road network data}

The free-flow travel time from each network entry point to each bookable loading bay was specified. These were obtained from a traffic simulation model of Winchester, developed using AIMSUN software.

\subsubsection{Vehicle data}

A total of 69 freight vehicles were estimated to serve Winchester High Street during the time period 06:00-16:00, where this number was estimated from field survey data. It should be noted that the number of vehicles is considerably fewer than the number of deliveries, reported earlier, as many, particularly courier vans, deliver to several stores. Of the estimated 69 vehicles, 49 vehicles (12 rigids, 17 vans and 20 service vehicles) were modelled as being potential users of the bookable loading bays, with the other 20 vehicles modelled as using other freight unloading points. For each vehicle, the following data were supplied:

- Vehicle type (e.g. rigid (delivery), van (delivery), service vehicle) 
- Entry point to the network, that is, one of the 8 approach roads to Winchester, used in determining the travel time from the entry point to the loading bay.

- Entry time to the network. Entry times were sampled at random and were modified between scenarios to assess the effects of vehicles arriving early or late.

- Desired loading bay and an alternative freight unloading point in case it was not available.

- Expected dwell time at the desired loading bay and at the alternative. The dwell times at each freight unloading point were assumed to vary according to the vehicle type and the walking distances from each point to the central part of the High Street (Table 1), with the times at the bookable loading bays (numbered 1 and 2) being the shortest as they were the most conveniently located. These times were based on previous surveys, undertaken in Winchester as part of the Green Logistics project (www.greenlogistics.org), that had indicated that the average times spent at a freight unloading point were around 10 minutes for courier vans, 20 minutes for rigid lorries and 35 minutes for service vehicles.

- The number of 15-minute time slots required by the vehicle at the bookable loading bay. These were assumed to be one, two and three, respectively, for vans, rigids and service vehicles, respectively.

Table 1. Assumed dwell times (minutes) by vehicle type and freight unloading point

\begin{tabular}{lccccccccc}
\hline & \multicolumn{1}{c}{ Freight unloading point no. } \\
\hline & 1 & 2 & 3 & 4 & 5 & 6 & 7 & 8 & 9 \\
rigid & 16 & 16 & 20 & 20 & 24 & 24 & 20 & 30 & 30 \\
van & 8 & 8 & 10 & 10 & 12 & 12 & 10 & 15 & 15 \\
service & 28 & 28 & 35 & 35 & 42 & 42 & 35 & 53 & 53 \\
\hline
\end{tabular}

Note: The freight unloading point numbers correspond to those used in Figure 3.

\subsubsection{Booking data}

The booking data for each bookable loading bay were output from the advance booking system model and comprised a list of vehicle identification numbers associated with the allocated time slots. An example is shown for a loading bay accommodating two vehicles at a time (Table 2).

Table 2. Example time slot bookings (vehicle identification numbers)

\begin{tabular}{lcccccccccc}
\hline booked time & $\ldots$ & 0800 & 0815 & 0830 & 0845 & 0900 & 0915 & 0930 & 0945 & $\ldots$ \\
\hline $1^{\text {st }} \begin{array}{c}\text { vehicle } \\
\text { identification no. }\end{array}$ & 12 & 12 & 14 & 15 & 15 & 17 & 17 & 17 & \\
$2^{\text {nd }} \begin{array}{c}\text { vehicle } \\
\text { identification no. }\end{array}$ & - & 13 & 13 & 13 & 16 & 18 & - & 19 & \\
\hline
\end{tabular}

\subsection{Performance criteria}

\subsubsection{Adherence to schedule}

The advance booking system may have an impact on the times at which freight vehicles enter the network. If the number of unloading spaces during the peak unloading period (0900-1200) is less than the existing demand for spaces then some peak spreading may occur. This depends, of course, on the desirability of the bookable loading bays and on the availability of other options for unloading. The 
differences in entry times between the 'before' case, which was assumed to represent the 'desired entry time', and the time that was available to be booked (not necessarily the desired entry time) in the 'after' case' was measured and used as an indicator of the impact of the booking system on entry times. These differences in entry times may have an effect on a freight operator's ability to keep a vehicle on schedule, however, it is difficult to quantify the effect, as it may depend on other work to be done outside Winchester, on how the Winchester deliveries fit into the schedule and the scope for redesigning schedules.

\subsubsection{Delivery time}

The delivery (or service) time was defined here to include:

- travel time from the network entry point to the loading bay, including any waiting time in a holding area (where an early vehicle has to wait to gain access to the bay)

- time needed to move goods from vehicle to store, which was calculated as a fixed, specified time for the individual vehicle plus any additional time needed as a result of having to park further away from the store than desired, or as a result of having to move the vehicle from the bookable loading bay to an alternative freight unloading point.

\subsubsection{Use of freight unloading points}

The use of the different available freight unloading points was monitored in the before and after scenarios to provide an assessment of any improvements in the legality or desirability of the freight unloading points that were used. Some unloading points were classed as 'illegal and/or undesirable', on the basis that they caused obstructions to other road users and/or presented safety hazards.

\subsubsection{General traffic delay}

Where a lorry causes an obstruction, by parking on a double yellow line, for example, there can be delay to general traffic. Example scenarios of this were modelled, using the Winchester AIMSUN network, to illustrate the effects of illegal freight unloading behaviour. Significant delays to traffic were observed as a result of this activity, reported by the authors in a previous paper (McLeod and Cherrett, 2009).

\section{Results}

\subsection{Impact of advance booking system on adherence to schedule}

The extent to which vehicles received their requested bookings, or bookings close to these, are shown for the cases with one space (Table 3) and two spaces at each loading bay (Table 4). From Table 3 it can be seen that rigid vehicles nearly always received their requested time, and, if not, the allocated time was close to the requested time. At loading bay one, only 3 out of 10 vans received their requested time but 6 others received a time within one hour of the requested time. More vans (5 out of 7) received their requested time at loading bay two as there was less demand for this loading bay, compared with loading bay one. After the rigid vehicles and vans had made their bookings, there were only a few 45-minute slots left available for service vehicles to book and often these were very early in the morning or late in the afternoon, which meant that any booking allocations made would not necessarily be acceptable or useful for the service vehicle driver. In practice, it may be desirable to 
design the booking system to try to maintain contiguous free slots to allow some longer bookings to be made, however this was not considered in this study.

Table 3. Number of vehicles obtaining booking slots with only one space available at each bay

\begin{tabular}{|c|c|c|c|c|c|c|c|c|}
\hline \multirow[b]{4}{*}{ Rigid vehicle } & \multicolumn{8}{|c|}{ Difference between requested and allocated time slots } \\
\hline & \multicolumn{4}{|c|}{ Loading bay 1} & \multicolumn{4}{|c|}{ Loading bay 2} \\
\hline & Zero & $\begin{array}{c}15-60 \\
\text { mins }\end{array}$ & $\begin{array}{l}>60 \\
\text { mins }\end{array}$ & $\begin{array}{l}\text { No slot } \\
\text { allocated }\end{array}$ & Zero & $\begin{array}{c}15-60 \\
\text { mins }\end{array}$ & $\begin{array}{l}>60 \\
\text { mins }\end{array}$ & $\begin{array}{l}\text { No slot } \\
\text { allocatec }\end{array}$ \\
\hline & 6 & 1 & 0 & 0 & 5 & 0 & 0 & 0 \\
\hline Van & 3 & 6 & 1 & 0 & 5 & 2 & 0 & 0 \\
\hline $\begin{array}{l}\text { Service } \\
\text { vehicle }\end{array}$ & 0 & 1 & 2 & 10 & 0 & 2 & 3 & 2 \\
\hline
\end{tabular}

Table 4. Number of vehicles obtaining booking slots with two spaces available at each bay

\begin{tabular}{|c|c|c|c|c|c|c|c|c|}
\hline & \multicolumn{8}{|c|}{ Difference between requested and allocated time slots } \\
\hline & \multicolumn{4}{|c|}{ Loading bay 1} & \multicolumn{4}{|c|}{ Loading bay 2} \\
\hline & Zero & $\begin{array}{c}15-60 \\
\text { mins }\end{array}$ & $\begin{array}{l}>60 \\
\text { mins }\end{array}$ & $\begin{array}{l}\text { No slot } \\
\text { allocated }\end{array}$ & Zero & $\begin{array}{c}15-60 \\
\text { mins }\end{array}$ & $\begin{array}{l}>60 \\
\text { mins }\end{array}$ & $\begin{array}{l}\text { No slot } \\
\text { allocated }\end{array}$ \\
\hline Rigid vehicle & 7 & 0 & 0 & 0 & 5 & 0 & 0 & 0 \\
\hline Van & 8 & 2 & 0 & 0 & 7 & 0 & 0 & 0 \\
\hline $\begin{array}{l}\text { Service } \\
\text { vehicle }\end{array}$ & 1 & 3 & 0 & 9 & 4 & 3 & 0 & 0 \\
\hline
\end{tabular}

Where the loading bay could accommodate two vehicles at a time (Table 4), rigid vehicles and vans nearly always received their requested time, and, if not, the allocated time was close to the requested time. The additional spaces also made it possible for 4 out of 13 service vehicles at loading bay one and all 7 service vehicles at loading bay two to obtain time slots within one hour of their requested times.

\subsection{Delivery times}

The impact of the booking and control system was investigated over a range of scenarios which varied the extent to which freight vehicles arrived early or late for their bookings. The scenarios were:

1. All vehicles arrive on time for their booking

2. Half of all vehicles arrive on time, half arrive 15 minutes late

3. Half of all vehicles arrive on time, half arrive 30 minutes late

4. Half of all vehicles arrive on time, half arrive 45 minutes late

5. Half of all vehicles arrive on time, half arrive 15 minutes early

6. Half of all vehicles arrive on time, half arrive 30 minutes early

7. Half of all vehicles arrive on time, half arrive 45 minutes early

8. The entry time of each vehicle was randomly chosen to be anywhere from 15 minutes early to 15 minutes late for its booking.

9. The entry time of each vehicle was randomly chosen to be anywhere from 30 minutes early to 30 minutes late for its booking.

10. The entry time of each vehicle was randomly chosen to be anywhere from 45 minutes early to 45 minutes late for its booking. 
11. The entry time of each vehicle was randomly chosen to be anywhere from 60 minutes early to 60 minutes late for its booking.

The relative dwell time for each scenario, compared with the base case scenario in which freight vehicles entered the network and used their favoured, non-bookable, unloading points, is shown in Figures 4 and 5, alongside the associated waiting time and moving delay, as defined earlier. When it was assumed that the loading bays could accommodate only one vehicle at a time (Figure 4) it can be seen that, with the exception of scenario 4, the introduction of the bookable loading bays reduced the dwell time for users of the system as a result of the improved access to the restricted part of the High Street. In the scenarios where some vehicles arrived early for their bookings (scenarios 5 to 11), these dwell time savings were offset by some vehicles having to wait at a holding area to gain access to the loading bay. In the worst case scenarios (7 and 11) individual vehicles had to wait up to 45 minutes to gain access to the bays and the total waiting time exceeded the dwell time savings. The modelled waiting times assume that drivers wait in a holding area rather than look for an alternative unloading point, which may not be the case for some drivers. In the scenarios where some vehicles arrived late (scenarios 2-4 and 8-11), the dwell time savings tended to reduce according to the number of vehicles and severity of the lateness and there was also a small amount of moving delay modelled (as defined in section 5.2).

$\square$ relative dwell time $\square$ waiting time $\square$ move delay

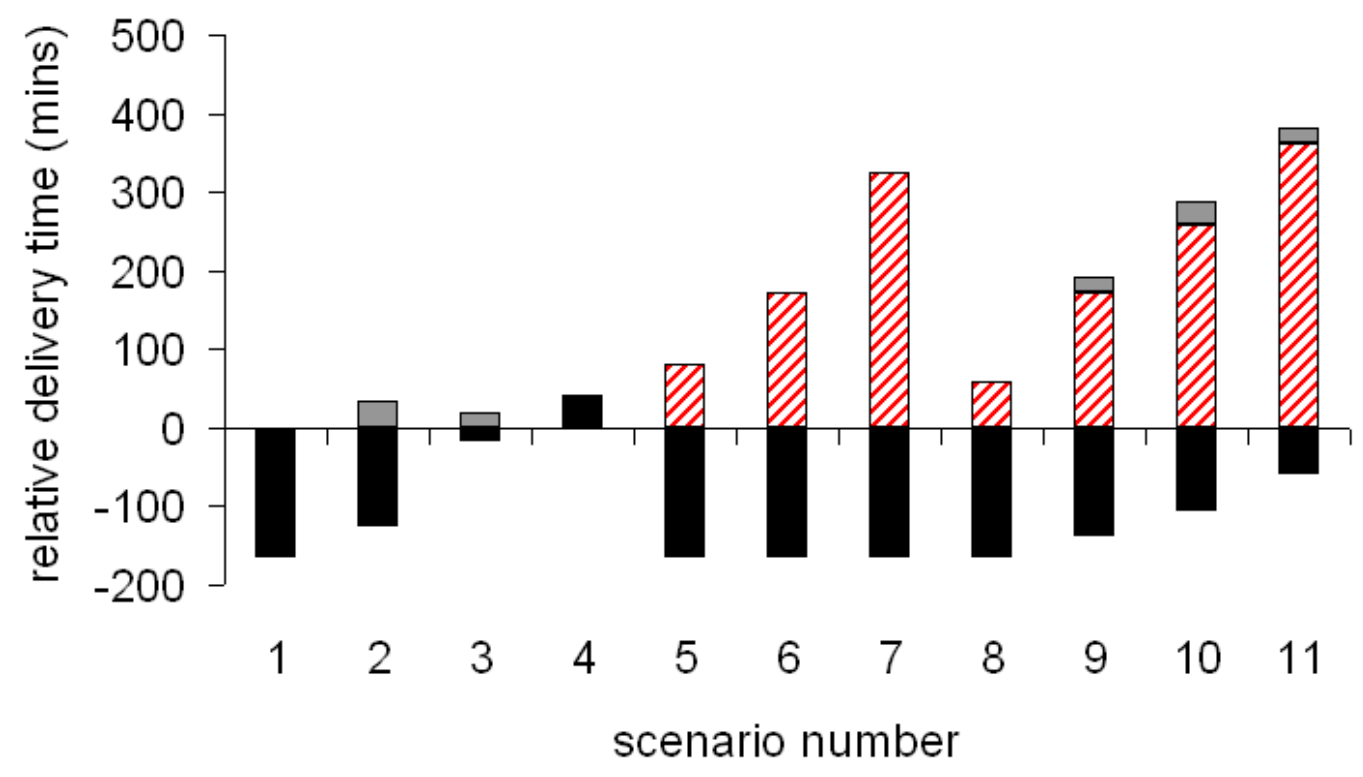

Figure 4. Effect on delivery times (one space at bays) 
When it was assumed that the loading bays could accommodate two vehicles at a time (Figure 5), the dwell time savings were considerably greater than before, at around 400 minutes totalled over the 49 modelled vehicles (around 8 minutes per vehicle). This was due to the fact that, with two spaces available at the bays, more vehicles could use the bookable loading bays, even if the vehicles were late. Similarly, the waiting times that were modelled were lower than in Figure 4, as vehicles were able to gain access to the bays quicker than before due to the additional spaces.

\section{relative dwell time $\mathbb{Z}$ waiting time $\mathbb{\mathbb { N }}$ move delay}

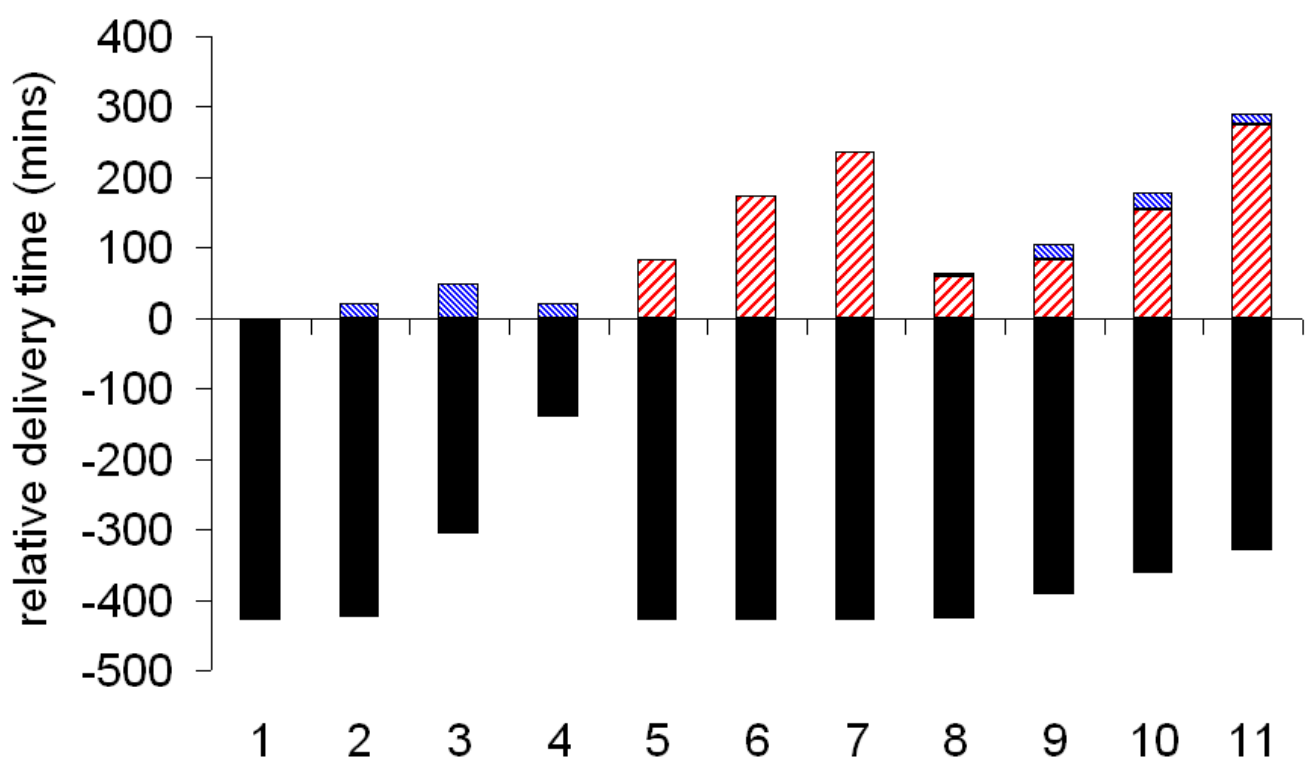

Figure 5. Effect on delivery times (two spaces at bays)

\subsection{Use of freight unloading points}

The usage of the various freight unloading points was monitored for each scenario and is shown for the case where the loading bays could accommodate one vehicle at a time (Figure 6). In this figure, the freight unloading points (numbered 1 to 9 in Figure 1) were categorised as 'bookable' ( 1 and 2), 'undesirable/illegal' (5, 6 and 7) and 'other' $(3,4,8,9)$. It was only in the 'before' case that the use of points 5, 6 and 7 was allowed. The greatest use of the bookable loading bays was seen in the scenarios where there were either no late vehicles (scenarios 1, 5, 6 and 7), or the level of lateness was small (scenario 8), as this meant that all of the vehicles with bookings could make full use of their slot. In those scenarios, the bookable loading bays were used for a total of 552 minutes. This usage represented only $46 \%$ of the total bookable time available (20 hours $=2$ bays $x 10 \mathrm{hr}$ booking period (0600-1600)). The reasons for this apparent low usage were that not all of the time slots could be booked (for example, a 30-minute gap could not be booked by a service vehicle needing a 45minute slot) and that many vehicles were modelled to exit the loading bay before the end of the booking since rigid vehicles were modelled to require only 16 minutes of their 30-minute booking; vans 8 minutes of their 15-minute booking and service vehicles 28 minutes of their 45-minute booking. 


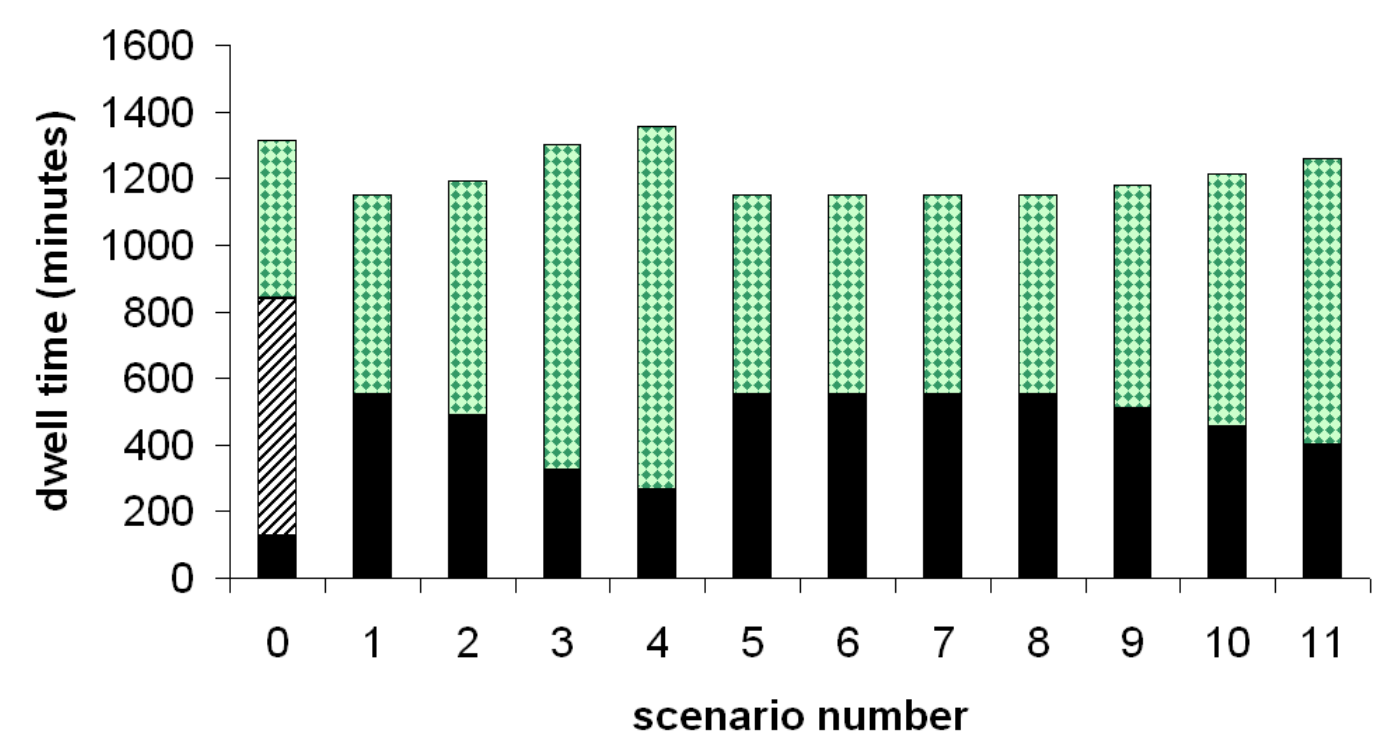

Figure 6. Use of freight unloading points (one space at bays)

In the scenarios where there were some considerably late vehicles (scenarios 2-4 and 9-11) the usage of the bookable loading bays reduced since these vehicles were liable to miss their booking entirely or to only be able to make partial use of their booking. The level of use of the bookable loading bays was dependent on the number of late vehicles and on how late the vehicles were in relation to the length of the booking made. For example, with half of the vehicles 15 minutes late (scenario 2) the bookable loading bay was used for a total of 489 minutes (compared with 552 minutes when all vehicles arrived on time (scenario 1)), and this reduced to 264 minutes when half of the vehicles were 45 minutes late (scenario 4 ).

\section{Discussion and conclusions}

The concept of advance booking and control of freight loading bays in an urban environment has been modelled for the city of Winchester. The results very much depend on the assumptions made about the sizes (i.e. how many vehicles can be accommodated) and locations of the bookable loading bays and of the alternative freight unloading points and of the system rules. Benefits to users of the system, in terms of reduced delivery times were demonstrated, where these derived from improved access to the High Street. These benefits would not be available if the bookable loading bays did not improve upon existing delivery options. Although this 'proof of concept' is for a relatively small urban area it has potential application in many other small towns, cities or districts/boroughs of larger cities.

A potential drawback to the usefulness and usability of pre-booked bays is the doubt about the ability of drivers to arrive in time for bookings. If the driver is early for a booking then he/she may have to wait in a designated holding area (any parking area reserved for lorries) on the outskirts of the city until the bay is free, or is predicted to become free soon. Alternatively, the driver may decide not to wait for the bay to become free, preferring to look for another option for unloading. If a driver is late 
then the booking may only be partially utilized or the booking may be missed entirely. The worst case scenario for the system, as specified here, would be where heavy congestion, due to a network incident, say, causes all vehicles to be late for bookings. In such a case, a more dynamic system, able to cope with perturbations, could possibly be more useful. An alternative approach would be to provide access to the loading bays on a first-come, first-served basis, under the control of a SmartFreight type system. This latter approach would be well-suited to dealing with dynamic situations; however, it would not have the advantages of the advance booking system whereby the freight distribution manager (and/or driver) can plan the vehicle schedule in advance based on bookings received, and the driver has a guaranteed space and does not have to wait for other vehicles to complete their deliveries. Further research is needed to assess the extent to which delivery drivers and service engineers are able to keep to schedules and, also, on driver/freight company attitudes to the usefulness of pre-booking spaces and their willingness to wait for the bay to become free.

From the city perspective, such a system may improve freight delivery behaviour and may reduce problems associated with parking on kerbs and double parking. Such a system may also encourage spreading of the delivery peak (09:00-12:00 hours in Winchester). This may be desirable to limit the numbers of large vehicles in the city centre at the same time, however, some cities (e.g. Gothenburg) are adopting policies to try to keep large vehicles out of the city centre after a certain time (e.g. 10am) so peak spreading may not be desired by some cities.

\section{References}

Browne, M., Allen, J. and Attlassy, M., 2007. Comparing freight transport strategies and measures in London and Paris, International Journal of Logistics Research and Applications, 10(3), 205-219.

Cherrett T. J., McLeod F. N., Maynard S.J. and Hickford A. J., 2010. The impacts of delivery and service vehicle activity in urban centres. Opportunities for 'green' logistics. Proceedings of the 89th Annual Meeting of the Transportation Research Board, Washington, D.C., USA., January, paper 101317

Cherrett T. J., McLeod F. N., Maynard S.J., Hickford A. J., Allen J and Browne M., 2009. Understanding retail supply chains to enable 'greener' logistics. Proceedings of the Logistics Research Network Annual Conference, Cardiff, UK, September 2009.

CVIS, 2010. UK test site experiences. CVIS Final Workshop - Validation \& Exploitation, Brussels, 21 May 2010. Available from: http://www.cvisproject. org/download/Events/validation_ws/CVIS_UK\%20TS_Validationworkshop_20100521.pdf [Accessed date 16 July 2010]

de Feijter, R., Evers, J.J.M. and Lodewijks, G., 2004. Improving Travel-Time Reliability by the Use of Trip Booking. IEEE Transactions on Intelligent Transportation Systems, 5(4), 288-292.

Edara, P. and Teodorovic, D., 2008. Model of an advance-booking system for highway trips. Trans. Res. C: Emerging Tech., 16(1), 36-53.

Feng, Y. and Xiao, B., 2006. A continuous-time seat control model for single-leg flights with no-shows and optimal overbooking upper bound. European Journal of Operational Research, 174 (2), 1298-1316.

Fowkes, A. S. , Firmin, P. E. , Tweddle, G. and Whiteing, A. E., 2004. How highly does the freight transport industry value journey time reliability — and for what 
reasons?, International Journal of Logistics Research and Applications, 7(1), 33-43.

McLeod, F.N. and Cherrett, T.J., 2009. Modelling the impacts of shared freight-public transport lanes in urban centres. Logistics Research Network conference, Cardiff, 2009.

McCrindle, S., 2008. Truck appointment systems. Successful Cooperative Intermodal Transport Strategies and ICT Systems workshop, 15-16 May 2008, Southampton. Available from: http://www.promit-project.net/ [Accessed date 16 July 2010]

Natvig, M., 2010. SmartFreight framework architecture. Available from: http://www.smartfreight.info/outcomes.htm [Accessed date 16 July 2010].

Wong, J.-T., 1997. Basic concepts for a system for advance booking for highway use. Transport Policy, 4(2), 109-114. 